\title{
TANGGUNG JAWAB BIDAN PRAKTIK MANDIRI DALAM MELAKUKAN TINDAKAN PERSALINAN LETAK SUNGSANG YANG MENYEBABKAN KEMATIAN BAYI DITINJAU DARI PERATURAN MENTERI KESEHATAN NOMOR 1464 TAHUN 2010 TENTANG IZIN DAN PENYELENGGARAAN PRAKTIK BIDAN DIHUBUNGKAN DENGAN STANDAR PROFESI BIDAN
}

\author{
Ayoe Apriani Pradana \\ Mahasiswa Pasca Sarjana Unisba Program Studi Magister Ilmu Hukum \\ E-mail : ayoeapriani@gmail.com
}

\begin{abstract}
Abstrak : Peraturan Menteri Kesehatan Nomor 1464 Tahun 2010 tentang Kesehatan telah mengatur bahwa bidan dalam melakukan tindakan harus sesuai dengan kewenangan dan Standar Profesi Bidan, dalam praktiknya banyak bidan yang melakukan tindakan persalinan diluar kewenangan dalam hal ini yaitu persalinan letak sungsang yang mengakibatkan kematian. Penelitian ini bersifat deskriptif analitis dengan menggunakan metode pendekatan yuridis normatif. Jenis data yang digunakan adalah data sekunder yang terdiri dari bahan hukum primer, sekunder, dan tersier yang berkaitan dengan tanggung jawab Bidan Praktek Mandiri (BPM) dalam melakukan tindakan pertolongan letak sungsang dengan kematian bayi. Teknik pengumpulan data dilakukan dengan studi lapangan dan studi kepustakaan, dan kemudian data yang telah diperoleh dianalisis menggunakan metode yuridis kualitatif. Hasil dari penelitian ini menunjukkan bahwa tanggung jawab Bidan Praktik Mandiri (BPM) yang melakukan tindakan persalinan diluar kewenangannya, akan mendapatkan sanksi administratif, sanksi pidana dan sanksi perdata.
\end{abstract}

Kata Kunci : Bidan, Tanggungjawab, Letak Sungsang

\begin{abstract}
Regulation of the Minister of Health Number 1464 Year 2010 on Health has stipulated that midwives in taking action must be following the authority and Midwives Professional Standard. In practice, many midwives carry out labor outside the authority for example in this case breech delivery resulting in death. This study used an analytical descriptive using normative juridical approach. The type of data used secondary data consisting of primary, secondary, and tertiary legal material relating to the responsibilities of Independent Practice Midwives (BPM/Bidan Praktek Mandiri) in carrying out breeches delivery with infant death. Data collection technique was conducted by field studies and literature studies, and then the result of data was analyzed using qualitative juridical method. The result of this study indicates that the responsibilities of Independent Practice Midwives who carry out labor outside their authority will get administrative sanctions, criminal sanctions, and civil sanctions.
\end{abstract}

Keywords: Midwife, Responsibility, Breech 


\section{A. PENDAhuluaN}

Angka Kematian Bayi (AKB)

di Indonesia masih tinggi. Berdasarkan Survei Demografi Kesehatan Ibu Indonesia (SDKI) tahun 2012, AKB mencapai 32 per 1000 kelahiran hidup. Sementara itu, laporan dari daerah yang diterima Kementerian Kesehatan menunjukan jumlah bayi yang meninggal di Indonesia berdasarkan estimasi SDKI 2012 mencapai 160.681 anak. Angka kematian bayi pada persalinan letak sungsang lebih tinggi bila dibandingkan dengan letak kepala. Angka kematian prenatal dengan persalinan letak sungsang mempunyai presentasse $16,8-38,5 \%$ di Indonesia.

Bidan dalam menjalankan praktek mandiri harus sesuai dengan kewenangan, kemampuan, pendidikan, pengalaman serta berdasarkan standar profesi. Salah satu standar profesi atau standar tindakan adalah tindakan kebidanan dilaksanakan sesuai dengan prosedur tetap dan wewenang bidan atau tugas kolaborasi, selain itu tindakan kebidanan dilaksanakan dengan merencanakan kode etik kebidanan, etika kebidanan serta mempertimbangkan hak klien aman dan nyaman. Namun masih sering dijumpai tindakan bidan tidak sesuai dengan wewenangnya. Tindakan melakukan persalinan letak sungsang merupakan tindakan diluar kewenangan dan kompetensi bidan praktik mandiri. Hal ini sesuai dengan Peraturan Menteri Kesehatan Nomor 1464 Tahun 2010 tentang kesehatan yang telah mengatur bahwa bidan dalam melakukan tindakan harus sesuai dengan kewenangan dan Standar Profesi Bidan.

\section{B. METODE}

Penelitian ini dilakukan dengan menggunakan pendekatan secara yuridis normatif, karena penelitian dilakukan berdasarkan data sekunder bahan hukum utama dengan cara menelaah teori-teori, konsep-konsep, asas-asas hukum serta peraturan perundang-undangan yang berhubungan dengan tanggung jawab bidan praktek mandiri (BPM) dalam melakukan tindakan pertolongan letak sungsang dengan kematian 
bayi. Spesifikasi penelitian yang digunakan adalah penelitian yang bersifat deskriptif analitis. Karena bertujuan memaparkan data hasil pengamatan tanpa pengujian hipotesis-hipotesis. Mengingat penelitian ini menggunakan yuridis normatif maka untuk mendapatkan data digunakanan teknik studi kepustakaan dan studi lapangan. Studi kepustakaan merupakan salah satu cara yang dipergunakan untuk memperoleh data sekunder yang diambil dari bahan pustaka sebagai bahan referensi sedangkan studi lapangan merupakan salah satu cara yang digunakan untuk memperoleh data primer dengan menggunakan tekhnik wawancara.

\section{HASIL}

Pasien Ny. A datang ke Bidan Praktik Mandiri bidan C pada pukul 23.30 WIB dengan keadaan ibu gelisah dan sudah merasakan tandatanda akan melahirkan yaitu mulesmules dan keluarnya lendir darah. Kemudian bidan C melakukan pemeriksaan, dengan hasil yang didapat Tekanan Darah: 120/70 mmHg, Suhu: $36^{\circ} \mathrm{C}$,Nadi: $\quad 78$ $\mathrm{x} /$ menit, Pernapasan: $20 \mathrm{x} / \mathrm{menit}$, ketuban masih utuh, presentasi terbawah janin yaitu bokong dan pembukaan sudah lengkap. Sejak melakukan prenatal care bidan tersebut telah mengetahui bahwa presentasi terbawah janin adalah bokong atau letak sungsang, tetapi bidan tersebut tetap melakukan tindakan persalinanletak sungsang.

Dengan hasil pemeriksaan tersebut, bidan tidak memungkinkan melakukan rujukan ke fasilitas kesehatan yang lebih tinggi. Pada saat itu juga bidan segera memimpin melakukan persalinan letak sungsang, namun dalam proses persalinan, ternyata bagian kepala sulit untuk dikeluarkan, yang pada akhirnya kepala tertinggal di dalam rahim dan mengakibatkan kematian bayi.

Kasus kedua, Pasien Ny.X datang ke Bidan Praktik Mandiri bidan $\mathrm{Z}$ pukul $01.00 \mathrm{WIB}$, dengan keadaan ibu gelisah dan sudah merasakan tanda-tanda akan melahirkan yaitu mules-mules dan keluarnya lendir darah. Kemudian bidan $\mathrm{Z}$ melakukan pemeriksaan, dengan hasil yang didapat Tekanan 
Darah: $\quad 110 / 80 \quad \mathrm{mmHg}$, Suhu: 36, $5^{\circ} \mathrm{C}$,Nadi: $\quad 80 \quad \mathrm{x} / \mathrm{menit}$, Pernapasan: 19 x/menit, ketuban masih utuh, presentasi terbawah janin yaitu kepala dan pembukaan 7 $\mathrm{cm}$ sehingga bidan $\mathrm{Z}$ menginformasikan kepada pasien dengan mengatakan keadaan ibu dan janin sehat, dan bisa melakukan persalinan di Bidan Praktik Mandiri tempatnya.

Pukul $05.15 \quad$ WIB ibu mengatakan mulesnya semakin kuat, sehingga dilakukan pemeriksaan dalam ulang, dengan hasil ketuban sudah pecah spontan dengan mekonium, presentasi terbawah janin berubah yaitu bokong dan pembukaan sudah lengkap. Berdasarkan hasil pemeriksaan ulang tersebut, bidan tidak memungkinkan melakukan rujukan ke fasilitas yang lebih tinggi. Segera bidan $\mathrm{Z}$ melakukan tindakan persalinan dengan letak sungsang sesuai SOP, hal yang tidak diduga kepala bayi sulit dikeluarkan. Pukul 06.30 bayi lahir dengan gaangguan pernafasan yang pada akhirnya bayi tidak betahan lama sehingga mengakibatkan kematian.

D. PEMBAHASAN

1. Tanggung Jawab Bidan dalam Melakukan Tindakan

Pertolongan Letak Sungsang yang Menyebabkan Kematian Bayi Menurut Peraturan Menteri Kesehatan RI No. 1464 Tahun 2010 Tentang Izin dan Penyelenggaraan Praktik Bidan dan Standar Profesi Bidan

a.Tanggung jawab moral

Tanggung jawab ini timbul apabila bidan dalam melaksanakan praktik mandiri telah melanggar norma-norma yang ada didalam masyarakat sehingga bertentangan dengan sumpah yang telah diucapkan pada saat bidan lulus dari pendidikan untuk dapat memberikan asuhan kebidanan kepada masyarakat.

\section{b.Tanggung jawab Etis}

Tanggung jawab ini berlaku dalam melaksanakan tugasnya yaitu melakukan prakek mandiri telah mengabaikan tugas yang diberikan untuk melakukan pelayanan kepada 
masyarakat atau menyimpang dari kode etik.

\section{c.Tanggung Jawab Secara Hukum}

1) Tanggung jawab hukum perdata

Dalam hal ini terdapat adanya perjajian antara bidan dengan pasien untuk membantu persalinan yang tentunya diharapkan berjalan dengan baik, namun kenyataannya bidan tidak memenuhi perjanjian tersebut. Dengan terjadinya wanprestasi tentu saja akan menimbulkan kerugian bagi pasien, oleh karena itu pasien berhak untuk menuntut ganti rugi. Hak pasien untuk mendapatkan ganti rugi atas suatu wanprestasi, di samping didasarkan pada ketentuan hukum perikatan juga didasarkan juga pada ketentuan hukum kesehatan sebagaimana yang diatur dalam Pasal 58 Undang-undang No. 36 Tahun 2009 Tentang Kesehatan yang menentukan bahwa: "Setiap orang berhak menuntut ganti rugi terhadap seseorang, tenaga kesehatan yang menimbulkan kerugian akibat kesalahan atau kelalaian dalam pelayanan kesehatan yang diterimanya".
Sedangkan gugatan berdasarkan perbuatan melawan hukum oleh pasien dapat dilakukan dengan mendasarkan ketentuan pada Undang-Undang Kesehatan maupun ketentuan yang diatur dalam KUHPerdata. Perbuatan melawan hukum selain perbuatan seseorang bertentangan dengan Undangundang, juga jika seseorang berbuat atau tidak berbuat yang melanggar hak orang lain, bertentangan dengan kewajiban hukum orang yang berbuat, berlawanan dengan kesusilaan, dan tidak sesuai dengan kepatutan dan kecermatan tentang diri atau benda orang lain dalam pergaulan hidup masyarakat. Dalam gugatan berdasarkan perbuatan melawan hukum, yang dimaksud kerugian juga meliputi kerugian materiil dan kerugian imaterial sebagaimana yang berlaku dalam gugatan berdasarkan wanprestasi.

2) Tanggung jawab hukum pidana

Tanggung jawab ini berlaku apabila dalam melaksanakan praktik mandiri mengakibatkan kerugian terhadap pasien dari akibat suatu 
kesalahan atau kelalaian berakibat fatal terhadap pasien, misalnya: cacat, bahkan kematian. Kelalaian yang mengakibatkan terancamnya keselamatan jiwa seseorang dapat diancam dengan sanksi pidana sebagaimana dimaksud dalam Pasal 360 Kitab Undang-Undang Hukum Pidana (KUHP) yang berbunyi :

a. Pidana penjara paling lama lima tahun atau kurungan paling lama satu tahun

b. Pidana penjara paling lama sembilan bulan atau kurungan paling lama enam bulan atau denda palingtinggi tiga ratus juta rupiah.

Dalam Kitab Undang-Undang Hukum Pidana (KUHP) kelalaian yang mengakibatkan celaka atau bahkan hilangnya nyawa orang lain diatur dalam Pasal 359 yng berbunyi : "Diancam dengan pidana penjara paling lama lima tahun atau kurungan paling lama satu tahun". Sanksi pidana yang diatur didalam Undang-Undang Kesehatan Nomor 36 Tahun 2009 adalah sebagai berikut : Tindak Pidana Sengaja Melakukan Tindakan Pada Ibu Hamil
(Pasal 194) Dipidana dengan pidanan penjara paling lama 10 (sepuluh) tahun dan denda paling banyak Rp. 1.000.000.000,00 (satu miliar rupiah).

3) Tanggung jawab hukum administratif

Adanya kesalahan dan kelalaian yang dilakukan bidan dan setelah dilakukan pemeriksaan atau analisa bahwa bidan telah melakukan tindakan diluar wewenang dan kaidah etik atau kaidah hukum maka akan berhubungan dengan pertanggungjawaban dalam hukum administrasi negara. Sanksi administrasi yang diberikan adalah sanksi disiplin yaitu berupa sanksi teguran baik lisan maupun tulisan sampai sanksi pencabutan izin praktik baik sementara mapun pencabutan selamanya yang dikeluarga oleh Kepala Dinas Kabupaten/Kota.

2. Implementasi Tanggung Jawab Hukum Bagi Bidan Praktik Mandiri atas Tindakan Bidan Dalam Melakukan Pertolongan Persalinan Letak Sungsang 
Bidan bertanggungjawab secara mutlak terhadap tindakan yang dilakukan maupun keputusan yang dibuat dalam memberikan jasa pelayanan kebidanan. Namun perbuatan bidan dalam menjalankan praktik seringkali masih terjadi kesalahan dan kelalaian sehingga mengakibatkan kerugian pada diri pasien dan perbuatan bidan tersebut seringkali disebut dengan tindakan bidan malpraktik. Salah satu solusi untuk penyelesainnya dilakukan oleh IBI, dimana IBI memberikan sanksi sesuai dengan peraturan-peraturan yang ada di IBI.

Sedangkan penyelesaian kasus malpraktik yang termasuk dalam kategori malpraktik perdata dapat dilakukan melalui dua cara, yaitu cara litigasi (melalui proses peradilan) dan cara nonlitigasi (diluar proses peradilan).apabbila dipilih cara litigasi atau melalui proses peradilan, maka pasien atau penggugat dappat mengajukan gugatannya dipengadilan negeri di wilayah kejadian. Apaila dipilih cara non litigasi atau diuar proses peradilan, maka kedua belak pihak, yaitu pasien dan bidan berupaya untuk mencari kesepakatan tentang penyelesaian sengketa. Dalam proses ini diupayakan mencari cara penyelesaian yang cenderung berdasarkan pemahaman kepentingan kedua pihak. Apabila, perbuatan bidan tersebut termasuk dalam kategori malpraktik pidana, maka kasus tersebut harus diselesaikan melalui jalur litigasi. karena dengan hukum perdata yang bertujuan untuk mencari perdamaian antara kedua pihak yang bersengketa atau dalam hal ini tenaga kesehatan dengan pasiennya.

\section{E. SIMPULAN}

Dari uraian hasil penelitian dan pembahasan dapat disimpulkan bahwa Tanggung jawab bidan praktik mandiri dalam melakukan tindakan darurat persalinan letak sungsang yang menyebabkan kematian bayi dihubungkan dengan Peraturan Menteri Kesehatan Republik Indonesia Nomor 1464 Tahun 2010 tentang Izin dan Penyelenggaraan Praktik Bidan dan Standar Profesi adalah tanggung jawab hukum perdata yang 
didasarkan Pasal 58 Undang-undang Kesehatan No 36 Tahun 2009 dilakukan berdasarkan wanprestasi karena adanya perjanjian dan yang didasarkan Pasal 1365 KUHPerdata perbuatan melawan hukum karena bidan telah melanggar peraturan, tanggung jawab hukum pidana yang mana tanggung jawab ini dalam melaksanakan praktik mandiri mengakibatkan kerugian terhadap pasien dari akibat suatu kesalahan atau kelalaian berakibat fatal terhadap pasien yaitu kematian bayi, tanggung jawab ini didasarkan Undang-undang Kesehatan No 36 Tahun 2009 dan yang didasarkan Pasal 360 KUHPidana, dan Tanggung jawab hukum administratif, dimana bidan dalam melakukan tindakan mengabaikan atau melanggar ketentuan yang sudah diatur dalam Peraturan Menteri Kesehatan Republik Indonesia No. 1464 Tahun 2010 tentang Izin dan Penyelenggaraan Praktik bidan, tanggung jawab administratif diatur dalam Pasal 188 Undang-undang No 36 Tahun 2009 tentang Kesehatan dihubungkan dengan Standar Profesi Bidan.

\section{F. SARAN}

1. Seorang bidan dalam menjalankan praktik harus selalu berpedoman pada kewenangannya yang diatur dalam Peraturan Menteri Kesehatan Republik Indonesia Nomor 1464 Tahun 2010 Tentang Izin dan Penyelenggaraan Praktik Bidan dan sesuai dengan Standar Profesi, agar tidak terjadi kesalahan dalam tindaknnya dan bisa mempertanggung jawabkannya.

2.

3. IBI dapat melaksanakan pengawasan secara rutin kepada bidan praktik mandiri dalam hal pemeriksaan sejauh mana tindakan pelayanan yang diberikan kepada pasien.

4.

5. Selain pengawasan dari IBI, pemerintah dalam hal ini Dinas Kesehatan harus melakukan pengawasan juga terhadap bidan praktik mandiri supaya menimbulkan efek jera dan bidan dalam melakukan praktiknya sesuai dengan kewenangannya. 


\section{DAFTAR PUSTAKA}

\section{AL-QURAN}

BUKU:

Algra, N.E., (et al), Kamus Istilah Hukum, Fockema Andrea, Diterjemahkan oleh Saleh Adiwinata, Binacipta, Bandung, 1983

Alexandra Indriyanti Dewi, Etika dan Hukum Kesehatan, Pustaka Book Publisher, Yogyakarta, 2008

Amri Amir,DSF, Bunga Rampai

Hukum Kesehatan, Widya Medika,

Jakarta, 1997

Andi hamzah, Kamus Hukum, Ghalia

Indonesia, 2005

Asri Hidayat dan Sujiatini, Asuhan Kebidanan dan Persalinan, Nuha Medika, Yogyakarta, 2010.

\section{Bagian Obstetri dan Ginekologi Fakultas Kedokteran Universitass Padjajaran Bandung, Obstetri Patologi, Bandung, Elstar Offset, 2005

\begin{tabular}{cl}
\hline & Obstetri \\
Bandung & Ginekologi, \\
\hline Bahder & Operatif, Bandung, 1987 \\
& Johan Nasution, Hukum \\
& Kesehatan Pertanggung \\
Jawaban Dokter, Rineka \\
Cipta, Jakarta, 2005 \\
Budiono, Kamus Lengkap Bahasa
\end{tabular}

Indonesia, Karya Agung, Surabaya, 2005

Buku Bantuan Bidan Siaga, Komunikasi Efektif Ibu Selamat, Bayi Sehat, Keluarga Bahagia

Buku Acuan Nasional, Pelayanan Kesehatan Maternal dan Neonatal, Cetakan1, YPBSP, Jakarta, 2008

Celina Tri Siwi Kristiyanti, Hukum Perlindungan Konsumen, Sinar Grafika, Jakarta

C.S.T. Kancil, Pengantar Hukum Kesehatan Indonesia, PT.Rineka Cipta, Jakarta, 1991

David T.Y Liu, Manual Persalinan

edisi 2, ecg, Bandung 2003

Departemen Kesehatan RI Kantor Wilayah Provinsi Jawa Barat, Buku I Standar Pelayanan Kebidanan, Bandung, 1999 
Dinas Kesehatan Provinsi Jawa Barat, Buku Saku Tenaga Kesehatan Provinsi Jawa Barat, FKPP, Bandung, 2003

Djoko Prakoso, Asas-Asas Hukum Pidana di Indonesia, Edisi Pertama, Liberty, Yogyakarta, 1987

Harmien Hadiati Koeswadji, Hukum Kedokteran di Dunia Internasional, makalah Simposium, Medical Law, Jakarta, 1993

\begin{tabular}{l}
\hline Kedokteran (Studi Trentang \\
Hubungan Hukum Dalam \\
Mana Dokter Sebagai Salah \\
Satu Pihak), PT. Citra Aditya \\
Bakti, Bandung, 1998
\end{tabular}

Ida Bagus Manuaba, Praktik dan Registrasi Bidan, ECG, Jakarta, 2000

Janus Sidabalok, Hukum Perlindungan Konsumen Di Indonesia, PT Citra Aditya Bakti, Bandung, 2006

Khairunnisa, Kedudukan, Peran dan Tanggung Jawab Hukum Direksi, Medan, Pasca Sarjana, 2008

Maimunah Sit,Kamus Istilah

Kebidanan, Jakarta, EGC,2005

Mansyur Efendi, Dimensi / Dinamika Hak Asasi Manusia Dalam Hukum Nasional Dan Internasional, Ghalia Indonesia, Jakarta, 1994

Martiman Prodjohamidjojo, Memahami Dasar-Dasar Hukum Pidana Indonesia, PT. Pradnya Paramita, Jakarta, 1997
Miru dan Yodo, Hukum Perlindungan Konsumen, Rajawali Pers, Jakarta, 2010

Mochtar Kusumaatmadja, Fungsi dan Perkembangan Hukum Dalam Pembangunan Nasional, Bina Cipta, Bandung, 1975

Pengurus Pusat Ikatan Bidan Indonesia, Etika dan Kode Etik Kebidanan, Jakarta, 2006

Nieuwenhuis, Pokok-Pokok Hukum Perikatan, terjemahan Djasadin Saragih, Universitas Airlangga, Surabaya, 1985

Pengurus Pusat Ikatan Bidan

Indonesia, Standar Profesi

kebidanan, Jakarta, 2006

Purbacaraka, Perihal Kaedah

Hukum, Bandung, Citra Aditya, 2010

Purwahid Patrick, Dasar-Dasar Hukum Perikatan (Perikatan yang Lahir dari Perjanjian dan UndangUndang), Mandar Maju, Bandung, 1994

Prajudi Atmosudirjo, Hukum Administrasi Negara, cetakan ke 10 Jakarta,Balai Aksara, 1994

Prawirohardjo sarwono, Ilmu

Kebidanan, Tridasa Printer, Jakarta, 2008

Retnowuan Susanto dan Iskandar Oeipkartawinata, Hukum Acara Perdata dalam 
Teori dan Praktek, cetakan ke 10, Mandar Maju, Bandung, 2005

Rianto Adi, Metode Penelitian Sosial

dan Hukum, Granit, Jakarta, 2004

Roscoe Pound, Pengantar Filsafat Hukum, Diterjemahkan dari edisi yang diperluas oleh Drs. Mohamad Radjab, Bhratara Karya Aksara, Jakarta, 1982

Ridwan H.R., Hukum Administrasi

Negara, Raja Grafindo Persada, Jakarta, 2006

R. Setiawan, Pokok-Pokok Hukum

Perikatan, Binacipta, Bandung, 1982

Sarwono Prawirohardjo, Ilmu

Kebidanan, Yayasan Bina Pustaka, Jakarta, 2002

Shidarta, Hukum Perlindungan

Konsumen, PT.Gransindo, Jakarta, 2000

Siti Ismijati Jenie, Tanggung Jawab Perdata di dalam Pelayanan Medis (Suatu Tinajuan dari Segi Hukum Perdata Materiil), Mimbar Hukum, Volume 18, Nomor 3, 2006

\begin{tabular}{ccc} 
Sofyan & \multicolumn{1}{c}{ Mustika, } & Bidan \\
& Menyongsong & Masa \\
Depan, Ikatan & Bidan \\
& Indonesia, Jakarta, 2001
\end{tabular}

Sugiyono, Metode Penelitian

Deskriptif, Alfabet,Bandung, 2010

Soekidjo Notoatmojo, Etika dan

Hukum Kesehatan, Rineka Cipta,

Jakarta, 2010

Soerjono Soekanto, Segi-segi Hukum Hak dan Kewajiban Pasien Dalam Kerangka Hukum Kesehatan, C.V.Mandiri Maju, Jakarta. 1990

, dan Sri Mamudji, Penelitian Hukum Normatif Suatu Tinjauan Singkat, Raja Grafindo Persada, Jakarta, 1994

Sri S, Saksi-Saksi Hukum, YBP-SS, Jakarta,1992

S.R Sianturi, Asas-Asas Hukum Pidana Indonesia dan Penerapannya, Cet.IV, Alumni, Jakarta, 1996

Sugiyono, Metode Penelitian

Deskriptif, Alfabet,Bandung, 2010

Sumarah, Yani Widyastuti, Nining Wiyati, Perawatan Ibu Bersalin, Fitramaya, Yogyakarta, 2008

Suwignyo Siswosuharjo dan Fitria Chakrawati, Panduan Super Lengkap Hamil Sehat, Penebar plus, Jakarta, 2008

Suwoto Mulyosudarmo, Peralihan Kekuassaan; Kajian Teoritis dan Yuridis Terhadap Pidato Newaksara, Gramedia, Jakarta, 1997

Titik Triwulan dan Shinta febrian, Perlindungan Hukum Bagi 
Pasien, Prestasi Pustaka, Jakarta, 2010

Veronica Komalawati, Peranan Informed Consent dalam Transaksi Terapeutik, PT.Cipta Aditya Bhakti, Bandung, 1999

Yanti dan W E Nurul, Etika Profesi dan Hukum Kebidanan, Pustaka Rihama, Yogyakarta, 2010

\section{PERUNDANG-UNDANGAN:}

Undang-Undang RI Nomor 36 Tahun 2009 Tentang Kesehatan

Undang-Undang RI Nomor 36 Tahun 2014 Tentang Tenaga Kesehatan

Undang-Undang RI Nomor 8 Tahun 1999 Tentang Perlindungan Konsumen

Peraturan Menteri Kesehatan RI Nomor 1464 Tahun 2010 Tentang Izin dan Penyelenggaraan Praktik Bidan Keputusan Menteri Kesehatan RI Nomor 900 Tahun 2002 Tentang Registrasi dan Praktik Bidan

Keputusan Menteri Kesehatan Nomor 369 Tahun 2007 Tentang Standar Profesi Bidan

\section{INTERNET:}

possore.com/2014/04/29/aki-danakb-masih-tinggi-kemkes- kampanye-peduli-kesehatanibu-2014

luciaindrian.blogspot.com/2011/05/le tak-sungsang-presbo.html, http://arinuramdhiani.blogspot.co.id/ 2013/04/normal-0-false-false-falsein-x-none-x.html http://aizizzahamir.wordpress.com/2 013/01

http://zippien.blogspot.com/2011/11/ tujuan-indonesia-sehat2015.html,

http://definisimu.blogspot.com/2012/ 08/definisi-pelayanankesehatan.html http://www.kompasiana.com/ http://dr-

suparyanto.blogspot.co.id/201 2/11/sekilas-tentangpersalinan.html

\section{TESIS:}

Siti Mulyani Ima, Tanggung Jawab Hukum Bidan dalam Melakukan Tindakan Debridment Luka Perinium Pada Ibu Pasca Salin Di Puskesmas Pelayanan Obstetri Neonatal Emergensi Dasar (PONED) Dihubungkan Dengan Undang-Undang Nomor 36 Tahun 2009 Tentang Kesehatan dan Permenkes Nomor 1464 Tahun 2010 tentang Izin dan Penyelenggaraan Praktik Bidan, Tesis, Bandung, 2015 
Ayoe Apriani Pradana, Tanggung Jawab Bidan Praktik Mandiri Dalam Melakukan Tindakan... 